\title{
Evaluasi Adopsi Inovasi Feed Additive Herbal untuk Ternak Ayam Pedaging
}

\author{
A. I. Sari \\ Program Studi Peternakan Fakultas Pertanian, Universitas Sebelas Maret, \\ Jl. Ir. Sutami 36 A, Surakarta 57126
}

\begin{abstract}
ABSTRAK
Penelitian ini bertujuan untuk mengevaluasi secara teknis dan ekonomi adopsi inovasi feed additive herbal untuk ternak ayam pedaging. Penelitian ini dilaksanakan pada bulan Agustus sampai Oktober 2008, pada peternakan ayam pedaging di Wilayah Kabupaten Karanganyar, Sragen, dan Boyolali dengan metode dasar penelitian deskriptif analisis. Responden penelitian sebanyak 34 peternak dipilih dengan metode purposive convinience sampling. Evaluasi teknis adopsi inovasi feed additive herbal dianalisis berdasarkan jawaban responden terhadap kuesioner yang menggambarkan proses adopsi inovasi, meliputi alasan utama peternak menerapkan inovasi, proses penerimaan inovasi, serta kesulitan atau hambatan dalam menerapkan inovasi. Evaluasi ekonomi inovasi feed additive herbal dianalisis berdasarkan perbandingan nilai pendapatan sebelum dan setelah menggunakan inovasi feed additive herbal. Hasil penelitian menunjukkan berdasarkan hasil evaluasi teknis terdapat perbedaan proses adopsi inovasi pada kategori adopter cepat dan lambat, yaitu pada alasan utama menerima inovasi dimana pada kategori adopter cepat dikarenakan produktivitas ternak lebih tinggi (52,94\%), sedangkan alasan utama untuk kategori adopter lambat dalam menerima inovasi karena menghemat biaya produksi $(47,06 \%)$. Hasil penelitian juga menunjukkan bahwa peternak kategori adopter cepat $(58,82 \%)$ tidak mengalami kesulitan dalam penerapan inovasi feed additive, sedangkan pada kategori adopter lambat (52,94\%) mengalami kesulitan dalam penerapan inovasi feed additive. Berdasarkan hasil evaluasi ekonomi, pendapatan usaha pemeliharaan ternak ayam pedaging tanpa menggunakan feed additive herbal pada skala usaha $\geq 8.000$ ekor sebesar Rp. 2.392,18 per ekor, skala usaha 3001-8.000 ekor sebesar Rp. 1.910,54 per ekor, dan pendapatan pada skala usaha $\leq 3000$ ekor sebesar Rp. 1.616,59 per ekor. Pendapatan usaha pemeliharaan ternak ayam pedaging dengan menggunakan feed additive herbal berdasarkan pada skala usaha $\geq 8.000$ ekor sebesar Rp. 2.557,19 per ekor, skala usaha 3001-8.000 ekor sebesar Rp. 2.176,12 per ekor, dan pendapatan pada skala usaha $\leq 3000$ ekor sebesar Rp. 1.767,15 per ekor. Kesimpulan dari penelitian ini adalah terdapat perbedaan hasil evaluasi tehnis adopsi inovasi feed additive herbal pada kategori adopter cepat dan lambat, yaitu pada alasan utama dalam menerima inovasi dimana kategori adopter cepat dikarenakan produktivitas ternak lebih tinggi, sedangkan kategori adopter lambat dalam menerima inovasi karena menghemat biaya produksi. Berdasarkan hasil evaluasi ekonomi, terjadi peningkatan pendapatan yang diterima peternak setelah menggunakan inovasi feed addite herbal, serta semakin besar skala pemeliharaan ternak ayam pedaging, maka tingkat keuntungan yang diperoleh juga semakin besar.
\end{abstract}

Kata kunci : Evaluasi teknis, evaluasi ekonomi, adopsi inovasi, feed additive herbal 


\title{
Evaluation on the Adoption of Herbal Feed Additive Innovation for Broiler
}

\begin{abstract}
The purpose of this research is to evaluate technically and economical adoption of herbal feed additive innovation for broiler. This research was conducted from August to October 2008, in the broiler farm at Karanganyar, Sragen, and Boyolali by using research based method of descriptive analysis. The respondents of the research were 34 farmers selected by using purposive convenience sampling. Evaluation technical adoption of herbal feed additive innovation, was analyzes base on the respondent's answer to questionnaire which draw a process adoption of innovation, consist of the first reason of farmer apply innovation, process receiving innovation and the difficulties and in apply innovation. The result of research shows based on technical evaluation result there differences adoption innovation process on adopter category early and late, it is first reason receive innovation where on early adopter category because on broiler production higher $(52,94 \%)$, while the first reason for late adopter category in receive innovation because to save production cost (47,06\%). The result also shows that early adopter category of farmers (58,82\%) not found difficulties in apply innovation feed additive, while in late category adopter (52,94\%) . Found difficulties in apply innovation feed additive. Base on economic evaluation value, the income of broilers farm without using feed additive herbal at scale $\geq 8.000$ broiler Rp 2.392,18 per broiler, scale 3001- 8.000 broilers Rp 1.910,54 per broiler, and the income at scale $\leq 3000$ broilers $R p$ 1.616,59 per broiler. Income of broilers farm with using feed additive herbal base on scale $\geq 8.000$ broilers Rp 2.557,19 per broiler, scale 3001- 8000 broilers Rp 1.767,15 per broiler. The conclusion from this research are different evaluation score technical adoption innovation feed additive herbal at the early and late adopter category, it is on the first reason in receive innovation where the early adopter category because of the broilers productivity higher, while late adopter category in receive innovation because the save the production cost. Base on economic evaluation result, there is increase income received by farmers after using innovation feed additive herbal and more scale broilers farm, so the advantage which get also bigger.
\end{abstract}

Key words: Technical evaluation, economic evaluation, adoption invation, herbal feed additive

\section{PENDAHULUAN}

Industri pangan telah mengalami perubahan konsep, dari pemuas rasa lapar menjadi pencapaian hidup sehat yang membawa dampak pertumbuhan kebutuhan kualitas bahan pangan (Kortz dan Story, 1994 cit. Syahlani, 2007). Peningkatan ini menimbulkan permintaan dan konsumsi produk yang terkait dengan pemeliharaan kesehatan tubuh (Moorman dan Matulich, 1993) dan pangan yang berpengaruh positif terhadap kesehatan (Worsley dan Scoot, 1999 cit. Syahlani, 2007). Pendapat ini didukung adanya fenomena bahwa saat ini gerakan gaya hidup sehat sedang melanda dunia, yang bertemakan back to nature. Tren baru tersebut telah bermunculan, masyarakat menginginkan makanan yang alamiah, rendah atau bahkan bebas dari zat kimia, pestisida, hormon, dan pupuk kimia. Pangan organik dianggap memenuhi persyaratan tersebut sehingga permintaan dan peluang pemasarannya meningkat. Khomsan (2004) menjelaskan pangan organik adalah semua jenis pangan yang berasal dari organisme hidup baik hewan maupun tumbuhan. Organik sendiri berarti sesuatu yang mengandung karbon. Istilah pangan organik secara terbatas dikenakan pada produk pangan yang diusahakan tanpa menggunakan bahan kimia, seperti pestisida dan pupuk buatan. 
Menanggapi permintaan dan peluang pemasaran pangan organik yang semakin meningkat, saat ini dibidang peternakan juga telah ditemukan suatu inovasi untuk mengurangi pemakaian bahan kimia selama proses produksinya. Sistem produksi peternakan yang bebas bahan kimia telah menghasilkan produk peternakan organik, diantaranya adalah daging ayam organik dan telur organik. Produk ini antara lain dihasilkan dengan aplikasi produk herbal yang bahan dasarnya didapatkan dari alam, dan difungsikan sebagai aditif pakan untuk ternak sehingga terbentuk immune suportif secara alami pada diri ternak.

Inovasi sebagai suatu ide, perilaku, informasi, produk, dan praktek-praktek baru yang belum banyak diketahui oleh masyarakat (Mardikanto,1993), tidak akan langsung dapat diterima dan digunakan dalam jangka waktu yang cepat dan bersamaan (Rogers, 1995). Masyarakat membutuhkan waktu untuk mengambil keputusan dalam menerima atau menolak inovasi (Soekartawi, 2005). Terdapat banyak faktor yang mempengaruhi kecepatan adopsi inovasi, yaitu sifat inovasinya sendiri, sifat sasarannya, cara pengambilan keputusan, saluran komunikasi yang digunakan, keadaan penyuluh, dan ragam sumber informasi (Mardikanto, 1993). Suatu inovasi akan mudah diterima sasaran apabila inovasi tersebut secara ekonomi menguntungkan, biaya awal yang rendah, resiko kecil, hemat tenga kerja dan waktu, dapat meningkatkan prestise dan kepuasan psikologis, serta secara teknis mudah dilakukan (Ibrahim et al., 2003).

Penelitian ini bertujuan untuk menganalisis secara teknis dan ekonomi adopsi inovasi feed additive herbal untuk ternak ayam pedaging. Evaluasi teknis merupakan penilaian terhadap proses adopsi dari inovasi feed additive herbal yang meliputi alasan utama peternak menerapkan inovasi, proses penerimaan inovasi, serta kesulitan atau hambatan dalam menerapkan inovasi, sedangkan evaluasi ekonomi meliputi penilaian terhadap efisiensi ekonomi yang ditimbulkan dengan penerapan inovasi feed additive herbal pada ternak ayam pedaging.

\section{MATERI DAN METODE}

Penelitian dilaksanakan pada bulan Agustus sampai dengan Oktober 2008 pada peternakan ayam pedaging di Wilayah Kabupaten Karanganyar, Sragen,dan Boyolali. Materi dalam penelitian ini meliputi peternak ayam pedaging sebanyak 34 peternak. Instrumen atau alat pengumpul data yang digunakan dalam penelitian ini adalah kuesioner. .Inovasi feed additive herbal yang digunakan dalam penelitian ini adalah Formula Integral Organik untuk Ternak (FIOT) yang diproduksi oleh PT. NATURAID.

Metode dasar yang digunakan dalam penelitian ini adalah metode deskriptif analisis, yang bertujuan melukiskan secara tepat sifatsifat suatu individu, keadaan, gejala, dan sebagainya yang merupakan obyek penelitian. Pelaksanaannya meliputi pengumpulan data, analisis, serta intepretasi data. Pengambilan peternak sebagai responden penelitian dilakukan dengan purposive convinience sampling, yaitu peternak yang pada saat penelitian masih memelihara ternak ayam pedaging dan menggunakan inovasi FIOT sebagai feed additive dalam pemeliharaan ternaknya, serta mau dijadikan responden penelitian. Data yang dibutuhkan dalam penelitian ini meliputi data primer dan data sekunder.

Evaluasi cepat lambatnya adopsi inovasi dalam penelitian ini dilakukan selama satu tahun sejak produk diluncurkan. Peternak yang sudah mengadopsi inovasi feed additive herbal sebelum enam bulan setelah produk tersebut diluncurkan masuk kedalam kategori adopter cepat (early adopter). Peternak yang mengadopsi inovasi feed additive herbal sesudah enam bulan produk tersebut diluncurkan, maka dimasukkan ke dalam kategori adopter lambat (late adopter). 


\section{Analisis Data}

Evaluasi teknis adopsi inovasi feed additive herbal dianalisis berdasarkan jawaban responden terhadap kuesioner yang menggambarkan proses adopsi inovasi, meliputi alasan utama peternak menerapkan inovasi, proses penerimaan inovasi, serta kesulitan atau hambatan dalam menerapkan inovasi. Jawaban responden kemudian ditabulasi dan dipersentase pada setiap kategori adopter. Evaluasi ekonomi inovasi feed additive herbal dianalisis berdasarkan perbandingan nilai pendapatan sebelum dan setelah menggunakan inovasi feed additive herbal. Pendapatan dari usaha peternakan ayam pedaging dihitung berdasarkan selisih antara total penerimaan dengan total biaya (Soekartawi, 1989).

Rumus yang digunakan :

$$
\begin{aligned}
& \mathrm{Pd}=\mathrm{TR}-\mathrm{TC} \\
& \mathrm{TC}=\mathrm{FC}+\mathrm{VC}
\end{aligned}
$$

dimana :

$$
\begin{aligned}
& \mathrm{Pd}=\text { Pendapatan }(\mathrm{Rp} / \text { periode }) \\
& \mathrm{FC}=\text { Biaya tetap }(\mathrm{Rp} / \text { periode }) \\
& \mathrm{VC}=\text { Biaya variabel }(\mathrm{Rp} / \text { periode }) \\
& \mathrm{TC}=\text { Total biaya }(\mathrm{Rp} / \text { periode }) \\
& \mathrm{TR}=\text { Total penerimaan }(\mathrm{Rp} / \text { periode })
\end{aligned}
$$

\section{HASIL DAN PEMBAHASAN}

\section{Karakteristik Responden}

Karakteristik responden dalam penelitian ini meliputi umur, tingkat pendidikan formal, jumlah anggota keluarga yang terlibat, pengalaman beternak, jumlah kepemilikan ternak, serta perilaku komunikasi peternak yang ditunjukkan oleh tingkat kosmopolitan (Tabel 1). Responden penelitian memiliki kisaran umur antara 19 sampai dengan 61 tahun, dengan rata-rata umur peternak 37,88 tahun (Tabel 1). Peternak yang menjadi responden penelitian merupakan tenaga kerja dalam umur yang produktif (15-55 tahun). Lama pendidikan peternak rata-rata 10,85 tahun, hal ini menunjukkan bahwa peternak rata-rata pernah mengikuti pendidikan setingkat SLTA.

Jumlah anggota keluarga yang terlibat dalam kegiatan beternak ayam pedaging, baik secara fisik maupun pemikiran berkisar antara 1-5 orang dengan rata-rata 1,9 orang. Anggota keluarga yang terlibat dalam kegitan beternak ini adalah mereka yang sudah dewasa dengan usia diatas 15 tahun. Besarnya jumlah anggota yang terlibat dalam kegiatan beternak dikarenakan peternak yang menjadi responden dalam penelitian ini merupakan peternakan rakyat dengan skala usaha yang rendah, sehingga dengan melibatkan anggota keluarga dalam kegiatan beternak akan menekan biaya, terutama untuk biaya tenaga kerja.

Rata-rata pengalaman responden dalam beternak ayam pedaging adalah 3,85 tahun. Pengalaman terendah 0,5 tahun dan tertinggi 12 tahun. Jumlah kepemilikan ternak ayam pedaging berkisar antara 2000 ekor sampai dengan 15.000 ekor, dengan rata-rata kepemilikan sebesar 6411,77 ekor. Menurut SK Menteri Pertanian nomor 362/kpts/tn.120/1990 tentang ketentuan dan tatacara pelaksanaan pemberian ijin dan pendaftaran usaha peternakan, peternakan rakyat untuk ayam pedaging adalah peternak dengan skala usaha dibawah 15.000 ekor/siklus produksi. Dengan demikian peternakan yang menjadi responden penelitian merupakan peternakan rakyat.

Karakteristik responden berdasarkan kategori tingkat kosmopolitan dapat dilihat pada Tabel 1. Responden yang termasuk dalam kategori tingkat kosmopolit tinggi sebanyak 18 orang (52,94\%), kategori tingkat kosmopolit rendah sebanyak 16 orang atau $(47,06 \%)$. Hal ini menunjukkan sebagian besar responden memiliki tingkat kosmopolitan yang tinggi.

\section{Kategori Adopter Inovasi Feed Additive Herbal}

Individu dalam suatu kelompok sosial tidak semuanya akan mengadopsi inovasi dalam waktu yang bersamaan tetapi dalam 
Tabel 1. Karakteristik responden penelitian

\begin{tabular}{lc}
\hline \hline \multicolumn{1}{c}{ Variabel } & Rata-rata \\
\hline Rata-rata umur (tahun) & 37,88 \\
Rata-rata tingkat pendidikan formal (tahun) & 10,85 \\
Rata-rata jumlah anggota keluarga yang terlibat (orang) & 1,91 \\
Rata-rata pengalaman beternak (tahun) & 3,85 \\
Rata-rata jumlah kepemilikan ternak (ekor) & 6411,77 \\
Tingkat kosmopolitan (\%) & \\
- Persentase tingkat kosmopolitan tinggi & 47,06 \\
- Persentase tingkat kosmopolitan rendah & 52,94 \\
\hline
\end{tabular}

waktu yang berbeda. Setiap individu dapat diklasifikasikan dalam kategori adopter berdasarkan pertama kali mereka menerapkan sebuah ide atau produk baru (Rogers, 1995). Kategori adopter menurut Van den Ban dan Hawkins (1999) dibagi menjadi lima kategori yang diperoleh dari perhitungan indeks adopsi, yaitu klasifikasi pelaku adopsi inovasi digambarkan sebagai suatu kelompok yang mengikuti distribusi normal. Rogers (1971) cit. Mardikanto mengemukakan hipotesisnya bahwa setiap kelompok masyarakat terbagi menjadi lima kelompok individu berdasarkan tingkat kecepatannya mengadopsi inovasi, yaitu innovators, early adopters, early majority, late majority, dan laggards.

Hasil penelitian menunjukkan bahwa $50 \%$ dari responden termasuk dalam kategori adopter cepat dan 50\% dikategorikan dalam adopter lambat. Hasil penelitian juga menunjukkan bahwa adopter cepat dalam penelitian ini meliputi innovators, early adopters, dan early majority, sedangkan adopter lambat meliputi late majority dan laggards.

\section{Evaluasi pada Setiap Kategori Adopter}

Feed additive atau aditif pakan merupakan bahan pakan yang tidak mengandung nutrien (non nutrien) yang ditambahkan dalam pakan ternak (Zuprizal, 2006), yang ikut tercerna atau membantu memperlancar proses pencernaan (Hardjosoebroto dan Astuti, 1993). Lebih lanjut Hardjosoebroto dan Astuti (1993) menyebutkan beberapa macam contoh aditif pakan yang sering diberikan pada ternak, antara lain antibiotik, fitobiotik, asam amino, enzimenzim, hormon, serta zat warna.

Seiring dengan kemajuan teknologi, saat ini banyak ditemukan feed additive yang beredar dipasaran yang semuanya memiliki keunggulan dalam memacu pertumbuhan ternak. Salah satu feed additive ternak yang saat ini mulai dilirik oleh banyak peternak adalah feed additive herbal, yaitu feed additive yang bahan dasarnya diperoleh dari alam. Aditif pakan yang dikalangan peternak lebih dikenal sebagai jamu-jamuan untuk ternak ini merupakan fitobiotik (Zainuddin, 2009). Fitobiotik (phytobiotics) merupakan aditif pakan yang murni berasal dari bahan tanaman (tumbuh-tumbuhan). Fitiobiotik memberikan efek positif terhadap penampilan ayam, seperti pertumbuhan yang ditunjukkan oleh pertambahan bobot badan ayam, konsumsi pakan, serta konversi pakan (Zuprizal, 2004).

Penggunaan fitobiotik yang bersifat herbal pada ternak ayam pedaging, akan mengarah pada terbentuknya produk daging ayam organik. Peternakan ayam organik bertujuan untuk menghapuskan atau mereduksi pemakaian obat-obatan antibiotik yang bersifat kimiawi pada ternak ayam. Penggunaan antibiotik tersebut dapat menyebabkan residu pada daging ayam sehingga apabila dikonsumsi 
oleh manusia secara terus menerus akan menimbulkan gangguan kesehatan (Saba et al., 2007).

Daging ayam organik memiliki beberapa keunggulan selain dari kandungan residu zat kimia yang rendah, antara lain daging lebih empuk (Saba et al., 2007), tidak berbau dan kadar airnya rendah (Hakim,2008). Keuntungan lainnya dari pemeliharaan ayam organik adalah biaya pemeliharaan yang lebih rendah karena pemakaian feed additive dapat mengurangi pemakaian obat-obatan (khususnya antibiotik). Kecenderungan konsumen untuk kembali ke alam menyebabkan harga jual daging ayam organik tinggi, sehingga margin keuntungan yang diperoleh peternak semakin besar (Saba et al., 2007).

Inovasi feed additive herbal memiliki karakteristik keuntungan relatif berupa kelebihan-kelebihan suatu inovasi, baik itu kelebihan ekonomi maupun non ekonomi. Kelebihan ekonomi meliputi efisiensi biaya, peningkatan keuntungan, serta kemudahan pemasaran, sedangkan non ekonomi dilihat dari aspek teknis seperti peningkatan produktivitas dan kekebalan ternak terhadap penyakit. Karakteristik kompatibilitas yang merupakan kesesuaian inovasi dengan tata nilai, adat istiadat yang sudah ada, pengalaman masa lalu dan kebutuhan penerima, ditunjukkan dari keramahan feed additive herbal pada lingkungan, karena tidak mengandung bahan kimia sehingga tidak berbahaya

Karakteristik kompleksitas berupa tingkat kesulitan inovasi feed additive herbal yang meliputi kesulitan cara penggunaan serta kesulitan mendapatkan produk feed additive herbal. Karakteristik triabilitas berkaitan dengan mudah atau tidak inovasi additive herbal dicoba dalam skala kecil. Karakteristik observabilitas berkaitan dengan mudah atau tidak suatu inovasi additive herbal dapat diamati baik proses maupun hasilnya oleh orang lain, seperti peningkatan produktivitas ternak yang ditunjukkan dari konsumsi pakan dan pertambahan bobot badan

\section{Evaluasi Teknis}

Penilaian mengenai adopsi inovasi feed additive untuk ternak ayam pedaging dilakukan melalui evaluasi teknis dan ekonomi terhadap inovasi tersebut. Evaluasi teknis tersebut meliputi alasan utama peternak menerapkan inovasi, proses penerimaan inovasi, serta kesulitan atau hambatan dalam menerapkan inovasi, sedangkan evaluasi ekonomi meliputi penilaian terhadap efisiensi ekonomi yang ditimbulkan dengan penerapan inovasi feed additive pada ternak ayam pedaging.

\section{Alasan utama menerima inovasi}

Hasil penelitian (Tabel 2) menunjukkan bahwa alasan utama responden kategori adopter cepat dalam menerima inovasi karena produktivitas ternak lebih tinggi (52,94\%), sedangkan alasan utama untuk kategori adopter lambat dalam menerima inovasi karena menghemat biaya produksi $(47,06 \%)$. Inovasi feed additive herbal mampu meningkatkan produktivitas ternak dipilih sebagai alasan utama yang melatar belakangi peternak kategori adopter cepat dalam menerima inovasi karena sesuai dengan pendapat Rogers (1995) yang menyatakan bahwa peternak yang masuk kategori adopter cepat memiliki kemampuan ekonomi yang lebih baik dibandingkan peternak kategori adopter lambat, sehingga dalam mengadopsi suatu inovasi yang menjadi pertimbangan utama adalah hal yang berkaitan dengan teknis, dan sebaliknya pada kategori adopter lambat yang menjadi pertimbangan utama adalah hal yang berkaitan dengan ekonomi, yaitu dalam hal ini yang dijadikan alasan utama bagi kategori adopter lambat adalah menghemat biaya produksi. 
Tabel 2. Evaluasi terhadap adopsi inovasi feed additive herbal pada masing-masing kategori adopter

\begin{tabular}{|c|c|c|c|c|}
\hline \multirow{2}{*}{$\begin{array}{c}\text { Variabel Evaluasi Teknis dan } \\
\text { Non Teknis }\end{array}$} & \multicolumn{2}{|c|}{ Adopter Cepat } & \multicolumn{2}{|c|}{ Adopter Lambat } \\
\hline & Jumlah & $\%$ & Jumlah & $\%$ \\
\hline \multicolumn{5}{|l|}{ Alasan Penerimaan Inovasi } \\
\hline a. Produktivitas ternak lebih tinggi & 9 & 52,94 & 5 & 29,41 \\
\hline b. Meningkatkan pendapatan & 3 & 17,65 & 2 & 11,76 \\
\hline c. Menghemat Biaya produksi & 2 & 11,76 & 8 & 47,06 \\
\hline d. Ramah Lingkungan & 3 & 17,65 & 2 & 11,76 \\
\hline Jumlah & 17 & 100 & 17 & 100 \\
\hline \multicolumn{5}{|l|}{ Proses Penerimaan Inovasi } \\
\hline a. Yakin dan langsung menerapkan & 5 & 29,41 & 2 & 11,76 \\
\hline b. Dicoba dulu dalam skala kecil & 12 & 70,59 & 14 & 82,35 \\
\hline c. Menungggu bukti dari peternak lain & 0 & 0 & 1 & 5,88 \\
\hline Jumlah & 17 & 100 & 17 & 100 \\
\hline \multicolumn{5}{|l|}{ Hambatan Dalam Penerapan Inovasi } \\
\hline $\begin{array}{l}\text { a. Tidak } \\
\text { b. Ya }\end{array}$ & 10 & 58,82 & 9 & 52,94 \\
\hline $\begin{array}{l}\text { 1. Produk hanya bisa dibeli melalui } \\
\text { tenaga penjual perusahaan/sales }\end{array}$ & 4 & 23,53 & 4 & 23,53 \\
\hline $\begin{array}{l}\text { 2. Informasi tentang feed additive } \\
\text { herbal terbatas }\end{array}$ & 1 & 5,88 & 2 & 11,76 \\
\hline $\begin{array}{l}\text { 3. Pemakaian feed additive herbal } \\
\text { memerlukan tenaga khusus }\end{array}$ & 0 & 0 & 0 & 0 \\
\hline 4. Harga feed aditif mahal & 0 & 0 & 0 & 0 \\
\hline 5. Lainnya & 2 & 11,76 & 2 & 11,76 \\
\hline Jumlah & 17 & 100 & 17 & 100 \\
\hline
\end{tabular}

Sumber : data primer diolah (2008).

\section{Proses penerimaan inovasi}

Sebagian besar peternak baik kategori adopter cepat $(70,59 \%)$ dan adopter lambat $(82,35 \%)$ akan mencoba suatu inovasi dalam skala kecil sebelum menerima suatu inovasi (Tabel 2. Hal ini mendukung pendapat Rogers dan Shoemaker (1971), yang menyatakan tahap keputusan inovasi dibuat berdasarkan evaluasi yang cukup melalui percobaan.

Percobaan penting dilakukan untuk mengadopsi atau menolak suatu inovasi. Percobaan tersebut dapat mengurangi ketidakpastian mengenai keuntungan atau kerugian yang ditimbulkan. Inovasi yang dapat dicoba dalam skala kecil lebih cepat diadopsi daripada inovasi yang tidak dapat dicoba. Adopsi inovasi yang sudah pernah dilakukan seseorang dengan baik dapat digunakan sebagai suatu percobaan.

Peternak yang dalam proses penerimaan inovasi yakin dan langsung menerima atau menerapkan inovasi untuk kategori adopter cepat $(29,41 \%)$ dan adopter lambat $(11,76 \%)$, sedangkan peternak yang dalam proses penerimaan inovasi menunggu keberhasilan peternak lain terlebih dahulu hanya terdapat pada kategori adopter lambat (5,88\%). Kondisi ini menggambarkan bahwa peternak yang masuk kategori adopter cepat lebih berani dalam menerima resiko dari setiap keputusan yang diambil, sehingga tanpa harus menunggu hasil percobaan atau menunggu keberhasilan peternak lain terlebih dahulu golongan ini sudah berani mengambil keputusan untuk mengadopsi suatu inovasi.

\section{Hambatan dalam penerapan inovasi}

Hasil penelitian (Tabel 2) menunjukkan bahwa peternak kategori adopter cepat $(58,82 \%)$ tidak mengalami kesulitan dalam 
penerapan inovasi feed additive, sedangkan pada kategori adopter lambat (52,94\%) mengalami kesulitan dalam penerapan inovasi feed additive. Banyaknya peternak kategori adopter lambat menemui kesulitan dalam menerapkan inovasi feed additive herbal, disebabkan sesuai dengan karakteristiknya peternak yang masuk kategori adepter lambat berumur lebih tua dan berpendidikan lebih rendah jika dibandingkan dengan peternak yang masuk kategori adopter cepat. Umur dan tingkat pendidikan akan mempengaruhi kapasitas belajar seseorang termasuk dalam memahami dan menerapkan suatu inovasi. Dahama dan Bhatnagar (1980) cit. Haryadi (1997) menyatakan kapasitas belajar akan terus naik sejak anak mulai mengenal lingkungan, dan kenaikan tersebut berakhir pada awal dewasa yaitu umur 15 tahun sampai 28 tahun, kemudian menurun, dan akan menurun secara drastis setelah umur 50 tahun. Mardikanto (1993) menambahkan bahwa tingkat pendidikan akan mempengaruhi kapasitas belajar seseorang, karena ada kegiatan belajar yang memerlukan tingkat pengetahuan tertentu untuk memahaminya.

\section{Evaluasi ekonomi inovasi feed additive herbal}

Salah satu keunggulan inovasi feed additive herbal adalah meningkatkan efisiensi ekonomi, yaitu dengan menekan biaya serta memperbesar pendapatan. Biaya usaha merupakan seluruh korbanan yang dikeluarkan sebagai biaya untuk memperoleh hasil selama periode usaha tertentu. Biaya usaha peternakan ayam pedaging terdiri dari biaya tetap (fixed cost) dan biaya tidak tetap (variable cost).

Tabel 3 menunjukkan bahwa pada biaya tetap komponen pengeluaran terbesar adalah penyusutan kandang dan peralatan yaitu berkisar antara 58\%-64\% dari total biaya tetap baik untuk skala rendah, sedang, dan tinggi. Bundy dan Diggins (1960), menyatakan bahwa pada kandang dan peralatan baik yang digunakan secara penuh atau tidak, mempunyai nilai penyusutan yang hampir sama.

Tabel 4 menunjukkan bahwa biaya variabel terbesar adalah digunakan untuk pembelian pakan (72\%), selanjutnya adalah untuk pembelian bibit atau DOC (22,3\%), sedangkan sisanya untuk komponen biaya variabel lainnya. Rata-rata biaya variabel, semakin besar skala pemeliharaan maka akan semakin besar biaya variabelnya, perbedaan ini biasanya terletak pada biaya upah untuk tenaga kerja. Kepemilikan ayam pedaging semakin besar maka upah tenaga kerja juga semakin besar dikarenakan membutuhkan tenaga fisik yang banyak serta ketrampilan dalam mengelolanya.

Tabel 4 juga menunjukkan bahwa terdapat selisih biaya variabel pemeliharaan ayam pedaging dengan menggunakan dan tanpa menggunakan inovasi feed additive herbal. Perbedaan itu terletak pada komponen pembelian obat-obatan dan pembelian feed additive herbal, serta pembelian pakan. Setelah menggunakan inovasi feed additive herbal biaya untuk penyediaan obat-obatan cenderung turun karena kekebalan tubuh ternak meningkat sehingga jarang terserang penyakit, sedangkan biaya untuk penyediaan pakan cenderung naik karena konsumsi pakan ternak meningkat.

Menurut Iskandar et al., (1993), penerimaan dalam peternakan ayam pedaging bersumber dari penjualan ayam, penjualan karung pakan, dan penjualan kotoran ayam. Tabel 5 menunjukkan bahwa sumber penerimaan terbesar adalah dari penjualan ayam yaitu sebesar 99\%. Penjualan karung pakan dan kotoran ayam juga merupakan sumber penerimaan lainnya dalam usaha peternakan ayam pedaging. Kondisi ini sesuai dengan pendapat Djanah (1984) yang menyatakan penjualan ayam merupakan sumber terbesar penerimaan peternakan ayam pedaging sebesar 98,5\%. Lebih lanjut dinyatakan bahwa penerimaan yang lain bersumber dari penjualan karung pakan sebesar $0,8 \%$, dan $0,7 \%$ dari penjualan kotoran ayam. 
Tabel 3. Rata-rata biaya tetap usaha ternak ayam pedaging dengan menggunakan dan tanpa menggunakan inovasi feed additive herbal (Rp/periode)

\begin{tabular}{llccc}
\hline \hline No & \multicolumn{1}{c}{ Uraian } & \multicolumn{3}{c}{ Skala Usaha (ekor) } \\
\cline { 3 - 5 } & & $\leq 3000^{1)}$ & $3001-8000^{2)}$ & $\geq 8000^{3)}$ \\
\hline 1. & Sewa tanah & $280.000,00$ & $558.366,67$ & $916.666,67$ \\
2. & $\begin{array}{l}\text { Pajak bumi dan bangunan } \\
\text { 3. }\end{array}$ & $3.100,00$ & $7.660,83$ & $15.199,80$ \\
& $\begin{array}{l}\text { Penyusutan kandang dan } \\
\text { peralatan }\end{array}$ & $400.400,00$ & $1.009 .822,17$ & $1.527 .266,40$ \\
\hline & \multicolumn{1}{c}{ Total } & $683.500,00$ & $1.575 .849,67$ & $2.459 .132,87$ \\
\hline
\end{tabular}

Keterangan : 1) $=5$ peternak

2) $=6$ peternak

3) $=5$ peternak

Sumber : data primer diolah (2008).

Tabel 4. Rata-rata biaya variabel usaha ternak ayam pedaging dengan menggunakan dan tanpa menggunakan inovasi feed additive herbal (Rp/periode)

\begin{tabular}{|c|c|c|c|c|c|c|c|}
\hline \multirow[t]{3}{*}{ No } & \multirow[t]{3}{*}{ Uraian } & \multicolumn{6}{|c|}{ Skala Usaha (ekor) } \\
\hline & & \multicolumn{2}{|c|}{$\leq 3000^{1)}$} & \multicolumn{2}{|c|}{$3001-8000^{2)}$} & \multicolumn{2}{|c|}{$\geq 8000^{3)}$} \\
\hline & & $\mathrm{A}$ & B & $\mathrm{A}$ & B & $\mathrm{A}$ & B \\
\hline 1. & DOC & $7.260 .000,00$ & $7.410 .000,00$ & $17.270 .833,00$ & $16.783 .333,30$ & $34.450 .000,00$ & $3.450 .000,00$ \\
\hline 2. & Pakan & $23.959 .000,00$ & $24.611 .010,00$ & $51.652 .873,00$ & $52.071 .606,00$ & $111.080 .538,00$ & $111.690 .150,00$ \\
\hline 3. & Obat-obatan & $699.000,00$ & $355.000,00$ & $1.423 .000,00$ & $1.100 .166,67$ & $2.551 .546,00$ & $1.856 .600,00$ \\
\hline \multirow[t]{2}{*}{4.} & Feed additive & & & & & & \\
\hline & & 0 & $115.000,00$ & 0 & $257.500,00$ & 0 & $515.000,00$ \\
\hline 5. & Listrik & $85.000,00$ & $85.000,00$ & $145.000,00$ & $145.000,00$ & $230.000,00$ & $230.000,00$ \\
\hline 6. & Upah & $550.000,00$ & $550.000,00$ & $1.033 .333,00$ & $1.033 .333,00$ & $1.430 .000,00$ & $1.430 .000,00$ \\
\hline 7. & Pemanas & $139.000,00$ & $139.000,00$ & $252.666,70$ & $252.666,70$ & $482.960,00$ & $482.960,00$ \\
\hline 8. & Sekam & $88.000,00$ & $88.000,00$ & $255.333,30$ & $255.333,30$ & $500.000,00$ & $500.000,00$ \\
\hline \multirow[t]{3}{*}{9.} & Perawatan & & & & & & \\
\hline & Kandang & $57.000,00$ & $57.000,00$ & $75.833,30$ & $75.833,00$ & $125.000,00$ & $125.000,00$ \\
\hline & Total & $33.520 .500,00$ & $34.093 .510,00$ & $73.684 .722,30$ & $73.550 .622,97$ & $153.309 .177,00$ & $153.738 .842,00$ \\
\hline
\end{tabular}

Keterangan : $\mathrm{A}=$ tanpa menggunakan feed additive herbal

$\mathrm{B}=$ dengan menggunakan feed additive herbal

1) $=5$ peternak

2) $=6$ peternak

3) $=5$ peternak

Sumber : data primer diolah (2008).

Tabel 5. Rata-rata nilai penerimaan usaha ternak ayam pedaging dengan menggunakan dan tanpa menggunakan inovasi feed additive herbal

\begin{tabular}{|c|c|c|c|c|c|c|c|}
\hline \multirow[t]{3}{*}{ No } & \multirow{3}{*}{$\begin{array}{l}\text { Nilai jual } \\
\text { (Rp/periode) }\end{array}$} & \multicolumn{6}{|c|}{ Skala usaha (ekor) } \\
\hline & & \multicolumn{2}{|c|}{$\leq 3000$} & \multicolumn{2}{|c|}{$3001-8000$} & \multicolumn{2}{|c|}{$\geq 8000$} \\
\hline & & A & B & A & $\mathrm{B}$ & A & B \\
\hline 1. & Ayam hidup & $37.054 .905,00$ & $37.988 .305,00$ & $83.581 .016,00$ & $84.682 .566,70$ & $179.358 .150,00$ & $181.635 .050,00$ \\
\hline 2. & Pupuk Kandang & $195.000,00$ & $195.000,00$ & $341.666,00$ & $341.666,67$ & $645.400,00$ & $645.400,00$ \\
\hline 3. & Karung Pakan & $186.000,00$ & $196.000,00$ & $391.666,00$ & $395.00,00$ & $410.000,00$ & $410.000,00$ \\
\hline \multicolumn{2}{|c|}{$\begin{array}{l}\text { Penerimaan } \\
\text { (Rp/ekor/periode) }\end{array}$} & $15.598,74$ & $15.973,64$ & $15.276,00$ & $15.526,94$ & $16.068,79$ & $16.269,71$ \\
\hline
\end{tabular}

Sumber : data primer diolah (2008). 
Tabel 6. Rata-rata nilai pendapatan usaha ternak ayam pedaging dengan menggunakan dan tanpa menggunakan inovasi feed additive herbal

\begin{tabular}{|c|c|c|c|c|c|c|c|}
\hline \multirow[t]{3}{*}{ No } & \multirow[t]{3}{*}{ "Uraian } & \multicolumn{6}{|c|}{ Skala usaha (ekor) } \\
\hline & & \multicolumn{2}{|c|}{$\leq 3000$} & \multicolumn{2}{|c|}{$3001-8000$} & \multicolumn{2}{|c|}{$\geq 8001$} \\
\hline & & $\mathrm{A}$ & $\mathrm{B}$ & $\mathrm{A}$ & $\mathrm{B}$ & $\mathrm{A}$ & $\mathrm{B}$ \\
\hline 1. & $\begin{array}{l}\text { Penerimaan } \\
\text { (Rp/periode) }\end{array}$ & $37.435 .905,00$ & $38.379 .305,00$ & $84.314 .350,00$ & $85.419 .233,33$ & $180.413 .550,00$ & $182.690 .450,00$ \\
\hline 2. & $\begin{array}{l}\text { Pengeluaran } \\
\text { (Rp/periode) }\end{array}$ & $33.520 .500,00$ & 34.093 .510 & $73.684 .722,17$ & $73.550 .622,17$ & $153.550 .622,17$ & $153.738 .842,80$ \\
\hline 3. & $\begin{array}{l}\text { Pendapatan } \\
\text { (Rp/ekor/periode) }\end{array}$ & $1.616,59$ & $1.767,15$ & $1.910,54$ & $2.176,12$ & $2.392,18$ & $2.557,19$ \\
\hline
\end{tabular}

Sumber : data primer diolah (2008).

Tabel 5 juga menunjukkan adanya perbedaan penerimaan dari usaha peternakan ayam pedaging dengan menggunakan dan tanpa menggunakan inovasi feed additive herbal, dimana berdasarkan hasil analisis penerimaan usaha peternakan ayam pedaging dengan menggunakan inovasi feed additive herbal lebih tinggi jika dibandingkan tanpa menggunakan inovasi feed additive. Kondisi ini dikarenakan rata-rata berat ayam hidup saat panen berbeda, dimana setelah menggunakan inovasi feed additive herbal rata-rata berat ayam hidup saat panen lebih tinggi. Ditambahkan oleh Djanah (1984) usaha peternakan ayam pedaging akan diperoleh hasil yang berbeda antara peternak yang satu dengan peternak yang lainnya yang disebabkan oleh ketrampilan yang berbeda antara masingmasing peternak.

Pendapatan merupakan nilai bersih yang terima peternak dari usaha peternakan ayam pedaging, yang diperoleh dari pengurangan total penerimaan dengan total biaya (tetap dan variabel). Tabel 6 menunjukkan bahwa pendapatan usaha pemeliharaan ternak ayam pedaging tanpa menggunakan feed additive herbal terbesar pada skala usaha $\geq 8.000$ ekor yaitu sebesar Rp. 2.392,18 per ekor. Pendapatan pada skala usaha 3001-8.000 ekor sebesar Rp. 1.910,54 per ekor, dan pendapatan pada skala usaha $\leq 3000$ ekor menunjukkan nilai yang paling kecil yaitu Rp. 1.616,59 per ekor.

Pendapatan usaha pemeliharaan ternak ayam pedaging dengan menggunakan feed additive herbal berdasarkan Tabel 6, terbesar pada skala usaha $\geq 8.000$ ekor yaitu sebesar $\mathrm{Rp}$. 2.557,19 per ekor. Pendapatan pada skala usaha 3001-8.000 ekor sebesar Rp. 2.176,12 per ekor, dan pendapatan pada skala usaha $\leq 3000$ ekor menunjukkan nilai yang paling kecil yaitu $\mathrm{Rp}$. $1.767,15$ per ekor. Kondisi ini menunjukkan perbedaan tingkat pendapatan yang diterima peternak dengan menggunakan dan tanpa menggunakan inovasi feed additive herbal, dimana terjadi peningkatan pendapatan setelah menggunakan feed additive herbal. Kondisi ini membuktikan bahwa penggunaan inovasi feed additive herbal memberikan keuntungan relatif. Hal ini juga membuktikan bahwa semakin besar skala pemeliharaan ternak maka tingkat keuntungan yang akan diperoleh juga akan semakin besar. Sesuai dengan pendapat Gusasi dan Saade (2006) bahwa semakin besar skala usaha peternakan ayam broiler maka tingkat keuntungan semakin tinggi.

\section{KESIMPULAN}

Hasil penelitian mengarahkan pada beberapa kesimpulan, antara lain :

1. Terdapat perbedaan hasil evaluasi tehnis adopsi inovasi feed additive herbal pada kategori adopter cepat dan lambat, yaitu pada alasan utama dalam menerima inovasi dimana kategori adopter cepat dikarenakan produktivitas ternak lebih tinggi, sedangkan kategori adopter lambat dalam menerima inovasi karena menghemat biaya produksi 
2. Terjadi peningkatan pendapatan yang diterima peternak setelah menggunakan inovasi feed addite herbal

3. Semakin besar skala pemeliharaan ternak ayam pedaging, maka tingkat keuntungan yang diperoleh juga semakin besar

\section{DAFTAR PUSTAKA}

Bundy, C.E. and R.V. Diggins. 1960. Dairy Production. Prentice Hall. Inc. New Jersey.

Djanah, D. 1984. Beternak Ayam dan Itik. Penerbit Yasaguna, Jakarta.

Hakim, A. 2008. Ayam Ajaib. www.Garasibu's Weblog. Accession date 17 Februari 2008.

Hardjosubroto, W. dan J.M. Astuti. 1993. Buku Pintar Peternakan. Penerbit Gramedia Widiasarana Indonesia, Jakarta.

Haryadi, F.T., R. Gayatri, R. Utomo. 2008. Early and Late Adopters in the Adoption Of Beef Cattle Concentrate Feed. Proseding Seminar Nasional The 13 th AAAP Animal Science Congres. Hanoi, Vietnam.

Haryadi, F.T. 1998. Efektivitas Penyuluhan Sapta Usaha Peternakan Sapi Potong Pada Dua Model Perkampungan Ternak. Buletin Peternakan Volume 23 No.3. Fakultas Peternakan UGM.

Iskandar, S.E. 1993. Analisa Ekonomi Tataniaga Ayam Ras Pedaging Pada Perusahaan Kecil di Bogor. BPTP Ciawi, Bogor.

Khomsan, A. 2004. Makanan Organik Sehat dan Segar. Sriwijaya Post.

Mardikanto, T. 1993. Penyuluhan Pembangunan Pertanian. Sebelas Maret University Press, Surakarta.
Mowan, J.C. dan M. Michael. 2002. Perilaku Konsumen. Penerbit Erlangga, Jakarta.

Rogers, E.M. 1995. Diffusion of Innovation. 4th ed., The Free Press, New York.

Rogers, E.M., and F.F. Shoemaker. 1971. Communication of Innovation, The Free Press, New York.

Saba, A., NF. Angga, dan M. Fauzan. 2007. Bussiness Plan Ayam Potong Organik. Fakultas Kedokteran Hewan UGM, Yogyakarta.

Soekartawi. 2005. Prinsip Dasar Komunikasi Pertanian. Penerbit Universitas Indonesia Press, Jakarta.

Syahlani, S.P. 2007. Kajian Efek Iklan dan Advertorial Pada Pengetahuan dan Persuasi Yang Dirasakan : Studi Proses Adopsi Pangan Fungsional. Jurnal Ekonomi dan Bisnis Indonesia. Volume 22 No. 1. Fakultas Ekonomi UGM, Yogyakarta.Van den Ban, A.W. dan H.S. Hawkins. 1999. Penyuluhan Pertanian. Penerbit Kanisius, Yogyakarta.

Zainuddin, D. 2009. Pemberian Feed Additive Herbal Dalam Ransum Terhadap Produktivitas dan Kesehatan Ternak Ayam Kampung Fase Pertumbuhan. Prosiding Seminar Nasional Kebangkitan Peternakan. Program Studi Magister Ilmu Ternak Fakultas Peternakan UNDIP, Semarang.

Zuprizal. 2004. Antibiotik, Probiotik dan Fitobiotik Dalam Pakan Unggas. Majalah Poultry Indonesia Edisi Januari 2004.

Zuprizal. 2006. Nutrisi Unggas. Bahan Ajar Jurusan Nutrisi dan Makanan Ternak, Fakultas Peternakan UGM, Yogyakarta. 